\title{
Asymmetric Information and Irreversible Investments: an Auction Model
}

\author{
Jøril Mæland \\ Norwegian School of Economics and Business Administration, Norway
}

The owner of a real option does not have the necessary expertise to manage the investment project and needs to contract with an expert in order to exercise the real option. The potential managers (the experts) have private information about their respective cost of investing in the project. The project owner organizes an auction in which the experts participate. The winner of the contract is the expert who can exercise the investment project at the lowest cost. The optimal contract is incentive compatible, i.e., it induces the winner to follow the investment strategy preferred by the project owner. It is shown that private information increases the project owner's cost of exercising the option, which may lead to under-investment. The inefficiency due to under-investment decreases in the number of experts participating in the auction. (JEL: G31, D82, G13)

Keywords: real options, investment strategy, private information, auction.

\section{Introduction}

Real option analyzes involve formulating projects as claims contingent on underlying assets, and making use of the analogy to financial option pricing theory in order to evaluate projects. Applying real option models the operating flexibility inherent in many projects is included in the project value, as is not the case when more traditional rules of capital

\footnotetext{
* I am grateful to Steinar Ekern for many useful comments and suggestions. Also, thanks to Bjarne Astrup Jensen, Diderik Lund, Kristian R. Miltersen, Petter Osmundsen, an anonymous referee, and participants of the 6th Annual International Conference on Real Options, Cyprus, July 4-6, 2002, for valuable comments. Address correspondence to Jøril Mæland, Norwegian School of Economics and Business Administration, Department of Finance and Management Science, Helleveien 30, N-5045 Bergen, Norway. Phone: +47 55 9593 13. E-mail: joril.maland@nhh.no.
}

(Multinational Finance Journal, 2010, vol. 14, no. 3/4, pp. 255-289)

(C) Multinational Finance Society, a nonprofit corporation. All rights reserved. DOI: $10.17578 / 14-3 / 4-4$ 
budgeting is used.

In traditional real option models it is typically assumed that information affecting option values and strategies is common knowledge. However, for many investment projects some uncertainty is privately revealed. For example, projects within natural resource exploration, information technology, and (other) research and development projects, often require specialized and technologically advanced investments. Thus, experts may have private information about variables affecting the values of such projects, and they can exploit this information in order to increase their profits at the expense of the project owner.

The purpose of this paper is to discuss how real option values and strategies are affected by agents with private information about the cost of making an investment. The model presented in this paper, as well as the short literature overview in section II, shows that asymmetric information may significantly change investment strategies and project values.

The benchmark model of the problem discussed is a classic real option problem: An owner of a right to invest in some project has the opportunity to invest at the time that maximizes the value of the project. Upon investment the owner obtains stochastic, positive cash flows from the project. Hence, the owner's optimization problem is to find the optimal time to invest, given uncertainty about project cash flows. Similar models are analyzed in McDonald and Siegel (1986), Paddock et al. (1988), Bjerksund and Ekern (1990), Dixit and Pindyck (1994), among others.

An incentive problem is introduced in the model by assuming that some agents have private information about their own respective (constant) costs of investing in the project. The owner of the project does not have the necessary expertise to make the investment, and he needs to contract with one of the privately informed agents in order to make the investment. The project owner organizes an auction, in which the privately informed agents participate, and the owner enters into a contract with one of the privately informed agents (i.e., with the "contract winner"). At the investment time the real option owner receives the observable value of the project, and transfers to the contract winner an amount that covers the reported investment cost, as well as a compensation based on the contract winner's value of private information. In our model the real option owner delegates the investment decision to the contract winner. However, we could just as 
well let the real option owner make the investment decision based on the contract winner's cost report, as the same investment strategy and values for the two parties apply in both cases. The project owner's problem is to find a contract that optimizes his value of the investment project, given the agents' private information.

The problem studied in this paper applies to many types of real options in which there is private information. One example is exploration of oil: Some areas where oil is found are difficult to explore and technologically advanced solutions are necessary in order to produce oil. Assume that an oil company with a right to produce oil does not have the required expertise and needs a supplier to provide necessary engineering services. The supplier has private information about costs of necessary investments. The supplying firm may try to exploit its private information by reporting higher investment costs than the true ones, in order to obtain a profit equal to the difference between the reported and the true investment costs. Typically there will be more than one firm with the necessary expertise, each having their own estimate of the costs of investment in equipment and engineering service, if they were to enter into a contract with the oil company. In accordance with the model presented in the paper, the oil company invites the "expert firms" to bid for the (incentive compatible) contract offered by the oil company. The winner of the contract will be the firm with that reports the lowest investment cost.

More generally, the model applies to real options in which the owner of the real option needs to rely on privately informed suppliers of technical solutions in order to exercise the real options. Often there exists more than one supplier possessing private information about technical solutions, and they compete about a right to manage the investment project. The model is restricted to situations in which the investment cost of each privately informed agent may be different, reflecting that the suppliers' qualifications may not be identical.

The incorporation of competition and privately informed agents into the real option model follows an approach similar to Laffont and Tirole (1987). In their paper it is assumed that the respective agents' private information is constant, and the model is formulated as a second-price sealed-bid private-values auction, also called a Vickrey auction. In such an auction, each bidder simultaneously submits a bid, without seeing others' bids, and the contract is given to the bidder who makes the best bid. However, the contract is priced according to the second-best bidder. In a Vickrey auction truth telling is a dominant strategy. 
Although we apply a Vickrey auction in the presentation below, it can be shown by the revenue equivalence theorem that under our assumptions the results do not depend on the organization of the auction. ${ }^{1}$

We find an optimal contract, in which the investment decision is delegated to the privately informed contract winner. The winner is the agent with the lowest cost report. The compensation to the winner depends on variables the project owner observes before the agents report their costs, in addition to the reported cost of the agent with the second-lowest cost. In the special case in which there is only one privately informed agent, the compensation function depends on ex ante observable variables, only. We show that private information increases the critical price of project implementation, because of an increased cost of exercising the option to invest. Thus, asymmetric information may lead to under-investment compared to the case of full information. Furthermore, we find that the optimal (second-best) investment strategy does not directly depend on the number of competitors (i.e., the number of privately informed agents), although the efficiency loss decreases in the number of competitors, as the winner of the contract probably will have a lower investment cost when there are many privately informed agents than when there are only a few. Thus, the project owner's option value increases in the number of privately informed agents for two reasons: First, a higher number of agents implies higher competition about the contract, and hence reduces each agent's value of private information. Second, in expectation the contract winner's cost level is lower the higher the number of privately informed agents.

The rest of the paper is outlined as follows. In section II we give a short overview of literature on real options and asymmetric information. The assumptions of the model developed in this paper are presented in section III, in addition to some results with respect to evaluation of the value functions. The agents' and the auctioneer's respective optimization problems are shown in sections IV and $\mathrm{V}$. The optimal contract is found in section VI. In section VII we illustrate the model through a numerical example.

1. The revenue equivalence theorem says that by any auction mechanism in which (i) the contract always goes to the buyer with the best bid, and (ii) any bidder with the worst bid expects zero surplus, yields the same expected revenue, and results in the same compensation as a function of his report. Thus, when the revenue equivalence compensation is satisfied, the expected outcome from the auction is the same no matter how the auction is organized. See Klemperer (1999), Myeers (1981), Riley and Samuelson (1981) and Vickrey (1961). 


\section{A short overview of real options and private information}

Over the last decade there has been a growing literature on real options and incentive problems, acknowledging that investment projects under uncertainty often involves asymmetric information between different parties involved in projects. In this literature real option theory and contract theory are combined, i.e., the uninformed and the informed parties enter into mutually beneficial contractual relationship.

Grenadier and Wang (2005), Mæland (2002), and Bjerksund and Stensland (2000) all formulate principal-agent models, in which an agent has private information about some parameter affecting value and optimal strategy of real options. The principal does not observe the value of this parameter, he or she only knows its probability distribution.

The setting in Grenadier and Wang (2005) is a shareholder owner and manager conflict: an owner (the principal) of an option to invest in a project delegates the investment decision to a manager (the agent) with private information about the value of the project upon investment. They find an optimal compensation contract to the manager. The compensation contract induces the manager to deliver to the owner the true value of the project. Private information implies that the manager is compensated higher than he or she would be full information. Furthermore, the manager will invest later than implied by a first-best solution.

Grenadier and Wang (2005) also include a moral hazard problem in the principal-agent problem: The manager can exert effort in order to influence the likelihood that the quality of the project is high or low. Interestingly, Grenadier and Wang (2005) show that the interplay between private information and hidden actions may reduce inefficiency in investment decisions, compared to the setting in which private information is the only agency problem. The reason is that the agent's option to exert effort mitigates the inefficiency problem due to private information.

Mæland (2002) formulates a similar model, but without hidden action, in which the principal is an owner of an investment project, and the investment decision is delegated to an agent. The agent has private information about the cost of exercising to investment option. In both Grenadier and Wang (2005) and Mæland (2002) the decisions delegated to privately informed agents are formulated as American call options: The problem is to find the optimal time to invest, given uncertainty 
about the asset value upon investment.

Bjerksund and Stensland (2000) formulate a production process that can be switched between two modes (on and off), and the processed output is sold at stochastic market prices. In absence of agency costs, this model is similar to the setting of Brennan and Schwartz (1985). Bjerksund and Stensland (2000) assume that the processing cost is privately observed by an agent.

In spite of different settings, the three models (Grenadier and Wang (2005), Maeland (2002) and Bjerksund and Stensland (2000)) give similar results: optimal compensations to the privately informed agents are found using a truth-telling incentive scheme (i.e., using the revelation principle). Thus, the principals compensate the agents according to their value of private information, implying a higher cost of exercising the principals' options. In other words, private information results in a higher critical value for investment, which may imply under-investment.

Mæland (2002) is the paper that is closest related to the model to be presented below. The main difference between the models in the two papers is that in Mæland (2002) only one agent has private information, whereas in the model to be presented below we take into account that several agents may have private information. We find that the optimal investment strategy is not altered when the number of privately informed agents changes. However, the project owner's option value is increasing in the number of privately informed agents, both because a higher number of agents reduces the contract winner's value of private information due to competition, and because of the ex ante expectation that the contract winner's investment cost level will be lower when the number of agents with private information is higher.

Antle et al. (2001) extend the private information problems above to situations in which the privately observed quantity changes stochastically. It is assumed that an agent has private information about the current cost of investing in a project, and that the owner of the investment opportunity only has an expectation of the cost. The investment cost changes stochastically, which means that none of the parties knows future states of the investment cost. As in the papers discussing constant private information, optimal (second-best) compensation functions are found, where the agent reveals his private information truthfully. A difference from the case of constant private information is that there are now two opposing effects that influence the investment strategy: As in the case of constant private information, the 
incentive problem implies a higher cost of exercising the option, thus leading to delayed investment. On the other hand, the inefficiency cost due to private information increases with time, giving the owner incentives to invest earlier. Hence, the total effect in the optimal investment strategy is ambiguous.

As in the problem to be presented below, Moel and Tufano (2000) discuss the effect of a combined auction and real options problem. The focus in the paper is, however, different: The paper analyzes an actual contract offered by a government, in which a copper mine were offered for sale through an auction. They show how the government's intentions of the sale were not fulfilled, because it did not take into account the option elements of the contract.

In the discussion above, only papers formulating agency settings are mentioned. Papers discussing non-agency settings where private information is conveyed about real options include Grenadier (1996, 1999). These papers study patterns of equilibrium option exercises due to revealed private information, and show that in some cases private information leads to information cascades or herding behavior.

\section{Economic Setting of the Model}

\section{A. Model Assumptions}

We assume that the owner of an investment project needs outside expertise in order to exercise the investment option, and enters into a mutually beneficial contract with an "expert firm". "Expert firms" will often be called agents in the following. There are $n$ agents with private information about the cost of exercising the investment project, and the investment cost is different for each agent. The $n$ agents compete about a contract that gives the winner the right to manage the investment strategy (or more specifically, gives the winner the right to decide on a stopping time), and to receive a compensation according to a pre-specified formula.

Each agent $i$ has private information about his own investment cost, $K^{i}$, but has no private information about the competitors' investment cost levels. We define the competitors' investment costs by the vector $K^{-i}=$ $\left(K^{1}, \ldots, K^{i-1}, K^{i+1}, \ldots, K^{n}\right)$. The owner of the investment project will often be called the auctioneer or the project owner in the following. The auctioneer does not observe any of the $n$ agents' investment cost 
parameter values, and each agent does not observe the other agents' cost levels. It is common knowledge that the investment cost levels are drawn independently from the same distribution. The cumulative distribution function is denoted $F(\cdot)$, and the lower and upper levels of possible investment cost outcomes are given by $\underline{K}$ and $\bar{K}$, respectively. ${ }^{2}$ We assume that $F(\cdot)$ is absolutely continuous. As the distribution $F(\cdot)$ is common knowledge, agent i's knowledge about the competitors' true investment cost is identical to the auctioneer's knowledge. The fraction $F(\cdot) / f(\cdot)$ is non-decreasing.

Upon investment the project owner obtains the stochastic value $S_{t}$, which is a function of positive, future cash-flow streams. We refer to $S_{t}$ as the asset value. The asset value is known by all the participants in the auction, including the auctioneer. Under the risk neutral measure, $Q$, the stochastic process is given by

$$
d S_{t}=\left(r S_{t}-\delta\left(S_{t}\right)\right) d t+\sigma\left(S_{t}\right) d B_{t}, \quad s \equiv S_{0} .
$$

The parameter $r$ denotes the yearly risk free rate, $\delta(\cdot)$ denotes the convenience yield function per year, $\sigma(\cdot)$ is the volatility function per year, and $B_{t}$ is a standard Brownian motion with respect to the equivalent martingale measure.

We define "ex ante" and "ex post" information as the information the project owner has before and after the owner receives cost reports from the agent. It is assumed that the project owner's ex ante information at time $t$ is given by $F_{t}^{S}$, generated by $\left\{S_{\xi}, \xi \leq t\right\}$. Define the vector of reports by $\hat{K}=\left(\hat{K}^{1}, \ldots, \hat{K}^{n}\right)$. The investor's ex post information is given by $F_{t}^{S, R},\left\{S_{\xi}, \hat{K}, \xi \leq t\right\}$. Each agent $i$ 's information at time $t$ is given by $F_{t}^{S, K^{i}}$ generated by $\left\{S_{\xi}, K^{i}, \xi \leq t\right\}$.

2. The assumptions that the cost parameters are different for the agents, and that the parameter values are independently drawn from the same distribution, are important for the results. An alternative assumption we could make about the agents' information, is that the true value is the same for everyone, but that the agents' have different information about the true value. In this case one agent learns about the true value if he observes another agent's signal. If these assumptions are made, the game is analyzed in a pure common-value model, whereas our assumptions about the agents' information above yield a private-value model, see an overview of auction theory by Klemperer (1999). We could also formulate models in which both kinds of information is present, i.e., in which the value of an object differs from agent to agent (for example because of subjective valuation), and in which at the same time each agent learns more about the value from others' signals. Klemperer (1999) refers to any model in which the value depends on some extent on others' bids, as common-value models. 
The function $X^{i}\left(S_{t}, \hat{K}\right)$ represents each agent $i$ 's expected gross compensation, received at the time the investment is exercised. By gross compensation we mean that the compensation $X^{i}$ is to cover agent $i$ 's expected investment cost, as well as agent $i$ 's value of private information. By expected compensation, we mean that $X^{i}$ is adjusted for agent $i$ 's probability of winning the contract. Observe that the compensation function may depend on the vector of all reports $\hat{K}=\left(\hat{K}^{1}, \ldots, \hat{K}^{n}\right)$, in addition to the observable quantities.

The auction is organized such that the agents simultaneously report their investment cost $\hat{K}=\left(\hat{K}^{1}, \ldots, \hat{K}^{n}\right)$ to the auctioneer.

Let $y^{i}(\cdot)$ be the ex ante probability that agent $i$ wins the project. We make the restrictions:

$$
\sum_{i=1}^{n} y^{i}(\hat{K}) \leq 1 \quad \text { and } \quad y^{i}(\hat{K}) \geq 0 \text { for any } \hat{K}
$$

The results of the auction lead to the same outcome whether it is the auctioneer or the winning agent who decides on the investment strategy. However, for the purpose of solving the model, we temporarily assume that the auctioneer decides on the investment strategy (i.e., on the optimal stopping time) based on the winning agent's cost report. The option to invest is assumed to be perpetual. The investment strategy, if agent $i$ wins the contract, is given by a stopping time $\tau_{R}^{i}$, indicating that the stopping time may be based on the reports given by the agents, in addition to the asset value $S_{t}$.

Agent $i$ 's value function $v^{i}(\cdot)$ equals the value of the compensation function reduced by the expected investment cost. The expected investment cost is adjusted for the probability of winning the contract, $y^{i}$, i.e.,

$$
v^{i}\left(s, K^{i} ; \hat{K}^{i}\right)=E\left[e^{-r \tau_{k}^{i}}\left(X^{i}\left(S_{\tau_{k}^{i}}, \hat{K}\right)-y^{i}(\widehat{K}) K^{i}\right)^{+} \mid F_{0}^{S, K^{i}}\right] .
$$

In the case in which there is only one agent with private information, the probability $y^{i}(K)$ equals one with certainty. However, when $n>1$ the investment cost is adjusted for the probability that agent $i$ wins the contract. Thus, competition implies that each agent's expected cost is lower than under no competition, and correspondingly, agent $i$ 's 
compensation is adjusted for agent $i$ 's probability of winning the contract. Furthermore, when $n>1$, equation (2) shows that the expected compensation $X^{i}(\cdot)$ and the investment strategy $\tau_{\hat{K}}^{i}$ may depend on the competitors' reports as well as the report of each agent $i$.

The auctioneer's value function is given by

$$
v^{P}(s)=E\left[\sum_{i=1}^{n} e^{-r \tau_{k}^{i}}\left(y^{i}(\hat{K}) S_{\tau_{R}^{i}}-X^{i}\left(S_{\tau_{R}^{i}}, \hat{K}\right)\right) \mid F_{0}^{S}\right]
$$

Equation (3) shows that the auctioneer's value of the investment depends on the net present value of future cash flows, reduced by the sum of the transfer functions $X^{i}(\cdot)$. The term $y^{i}(\hat{K}) S_{\tau_{K}^{i}}$ represents the asset value the auctioneer obtains at the investment time, adjusted for the probability that agent $i$ wins the contract. To find the auctioneer's asset value of the project, we need to sum up over all the agents participating in the contract, as is done in equation (3).

The auctioneer's incentive scheme is given by the control variables $\left(X^{i}(\hat{K}), \tau_{R}^{i}, y^{i}(\hat{K})\right)$. An important concept for solving private information models is the revelation principle. Loosely speaking, the revelation principle makes use of the fact that to each contract that leads to lying, there exists a contract with the same outcome, but where lying is not profitable. The revelation principle is often referred to as a truth telling constraint. ${ }^{3}$ Hence, we look for mechanisms $\left(X^{i}(\hat{K}), \tau_{\hat{K}}^{i}, y^{i}(\hat{K})\right)$ that induce truth telling Bayesian Nash equilibria. ${ }^{4}$

The optimization problem of the auctioneer is given by

$$
V^{P}(s)=\sup _{X^{i}, \tau_{k}^{i}, y^{i}} v^{P}(s)
$$

subject to each agent $i$ 's optimization problem,

3. Definition and prove of the revelation principle are shown in Salanié (1997) and Laffont and Tirole (1993), among others.

4. In a Bayesian Nash equilibrium each agent's reporting strategy is a function of his own information, and each agent maximizes his value function given the other agents' strategies, and given his beliefs about the other agents' information. A Bayesian Nash equilibrium is the appropriate equilibrium concept in auctions when asymmetric information exists. 


$$
V^{i}\left(s, K^{i} ; \hat{K}^{i}\right)=\sup _{\hat{R}^{i}} v^{i}\left(s, K^{i} ; \hat{K}^{i}\right) \quad \text { for } i=1, \ldots, n .
$$

Our aim is to find an optimal contract in which the investment strategy is delegated to the contract winner, whereas in the above formulation of the optimization problem, each agent $i$ only optimizes his value function with respect to the report $\hat{K}^{i}$. However, this is just a device in order to solve the problem. In section VI we find an implementable, optimal compensation in which the investment decision is delegated to the privately informed winner. In the formulation in equation (4) the auctioneer optimizes his value function with respect to incentive scheme, i.e., the compensation $X^{i}$, the stopping time $\tau_{R}^{i}$, and each agent $i$ 's probability of winning the auction, $y^{i}$.

\section{B. Evaluation of Expected Future Cash Flows}

In order to simplify calculations in the model, we evaluate the expected, future cash flows. Recall that we assume that the option to invest is perpetual. A time-homogeneous stochastic process implies that the investment strategy is time independent. Let $S^{i}(\hat{K})$ be the critical asset value. When $S_{t} \geq S^{i}(\hat{K})$ the strategy prescribes immediate investment, whereas the investment is postponed if $S_{t}<S^{i}(\widehat{K})$. Note that as the investment strategy $S^{i}(\hat{K})$ may depend on all the cost reports.

By a result from the theory of linear diffusions, ${ }^{5}$ the stochastic process of the asset value in equation (1) implies that the present value of one dollar received when a specified trigger $S_{i}$ is reached, can be expressed as ${ }^{6}$

$$
E\left[e^{-r r_{K}^{i}} \mid F_{0}^{S, K}\right]=\left\{\begin{array}{llc}
\frac{\phi(s)}{\phi\left(S^{i}(\hat{K})\right)} & \text { if } & s<S^{i}(\hat{K}) \\
1 & \text { if } & s \geq S^{i}(\hat{K})
\end{array}\right.
$$

where $\varphi(\cdot)$ is a strictly positive and increasing function. Defining

5. A linear diffusion is a one-dimensional, strong Markov process with continuous value paths taking values on an interval, see Borordin and Salminen (1996), ch. II.

6. Confer Itô and McKean (1965), section IV F, and Borodin and Salminen (1996), section II.10. 
$u(s)=E\left[e^{-r \tau_{k}^{i}} \mid F_{0}^{S, K}\right]$, the value of the discount factor satisfies the ordinary differential equation,

$$
\frac{1}{2}(\sigma(s))^{2} \frac{\partial^{2} u}{\partial s^{2}}+(r s-\delta(s)) \frac{\partial u}{\partial s}-r u(s)=0,
$$

with boundaries $\lim _{s \downarrow S^{i}(K)} u(s)=0$ and $\quad \lim _{s \uparrow S^{i}(K)} u(s)=1$. We interpret equation (6) as the value of the discount factor given that the vector of investment cost reports is known.

Using the result in equation (6), agent $i$ 's value function in equation (2) may be formulated as

$$
\begin{aligned}
v^{i}\left(s, K^{i} ; \hat{K}^{i}\right) & =E\left[\frac{\phi(s)}{\phi\left(S^{i}(\hat{K})\right)}\left(X^{i}\left(S^{i}(\hat{K}), \hat{K}\right)-y^{i}(\hat{K}) K^{i}\right) \mathrm{I}_{\left\{s<S^{i}(\widehat{K})\right\}}\right. \\
& \left.+\left(X^{i}(s, \hat{K})-y^{i}(\hat{K}) K^{i}\right) \mathrm{I}_{\left\{s \geq S^{i}(\hat{K})\right\}} \mid F_{0}^{S, K^{i}}\right],
\end{aligned}
$$

where $I_{\{A\}}$ is an indicator function of the event $A$. The first term inside the expectation brackets is agent $i$ 's value of the contract when the investment is postponed, given agent $i$ 's investment strategy. The difference $X^{i}\left(S^{i}(\hat{K}), \hat{K}\right)-y^{i}(\hat{K}) K^{i}$ is agent $i$ 's expected payoff from investment time. The expected payoff is discounted by $\phi(s) / \phi\left(S^{i}(\hat{K})\right)$. The second term represents agent $i$ 's expected payoff in a situation where the investment is made immediately under agent $i$ 's investment strategy. As the investment strategy $S^{i}(\widehat{K})$ may depend on competitors' unverifiable cost reports, agent $i$ must take the expectation over the set $K^{-i}$.

The auctioneer's value function in equation (3) is replaced by

$$
\begin{gathered}
v^{P}(s)=E\left[\sum _ { i = 1 } ^ { n } \left\{\frac{\phi(s)}{\phi\left(S^{i}(\hat{K})\right)}\left(y^{i}(\hat{K}) S^{i}(\hat{K})-X^{i}\left(S^{i}(\hat{K}), \hat{K}\right)\right) \mathrm{I}_{\left\{s<S^{i}(\hat{K})\right\}}\right.\right. \\
\left.+\left(y^{i}(\hat{K}) s-X^{i}(s, \hat{K})\right) \mathrm{I}_{\left\{s \geq S^{i}(\hat{K})\right\}} \mid F_{0}^{S}\right],
\end{gathered}
$$


when we use the relationship in equation (6). Analogously to the interpretation for agent $i$ 's value in equation (8), the first term inside the braces of equation (9) is the discounted value of the payoff received when agent $i$ 's investment strategy is followed: at a future investment time, corresponding to the time when the asset value reaches the investment trigger $S^{i}(\hat{K})$, the auctioneer receives the asset value, adjusted for the probability that agent $i$ wins the contract, minus the expected compensation for agent $i$. The second term inside the braces represents the auctioneer's value when agent $i$ chooses to invest immediately. The auctioneer's total value of the auction consists of each agent's contribution.

The reformulations of the auctioneer's and the agents' respective value functions simplify the optimization problem given by equations (4) and (5), as the value functions no longer are stochastic with respect to the value of the variable $S_{t}$. However, the value functions are still uncertain with respect to investment cost parameter values, as the auctioneer does not observe the vector of investment cost parameter values, and each agent only knows his own cost.

\section{Benchmark Model: Full Information}

In this subsection we will present the results if there is no private information, and use these results as a benchmark case. If the auctioneer has full information, each agent's value equals 0 as he has no private information. Then the auctioneer enters into a contract with the agent with the lowest investment cost. Now, let $K^{i}$ denote the lowest investment cost level. Under full information the contract winner's compensation at the investment equals his investment cost, i.e., $X^{i}=K^{i}$ in equations (8) and (9). Furthermore, given that agent $i$ is the winner of the contract, $y^{i}=1$. The formulation of the problem is then equal to the value of a perpetual call option of American type, which gives the option holder at any time the right to receive an asset by paying a pre-determined exercise price. The auctioneer's ex post value (i.e., the value given that the auctioneer observes the investment $\operatorname{cost} K^{i}$ ) is found by optimizing the auctioneer's value function with respect to the investment strategy. Thus, the auctioneer's value under full information is given by 


$$
\tilde{V}_{\text {full }}^{P}\left(s, K^{i}\right)=\left\{\begin{array}{lr}
\frac{\phi(s)}{\phi\left(S_{\text {full }}^{i^{*}}\left(K^{i}\right)\right)}\left(S_{\text {full }}^{i^{*}}\left(K^{i}\right)-K^{i}\right) & \text { if } s<S_{\text {full }}^{i^{*}}\left(K^{i}\right) \\
s-K^{i} & \text { if } s \geq S_{\text {full }}^{i^{*}}\left(K^{i}\right)
\end{array},(10)\right.
$$

where the optimal investment strategy under full information, $S_{\text {full }}^{i^{*}}\left(K^{i}\right)$, is given by

$$
S_{\text {full }}^{i *}\left(K^{i}\right)-K^{i}=\frac{\phi\left(S_{\text {full }}^{i *}\left(K^{i}\right)\right)}{\phi^{\prime}\left(S_{\text {full }}^{i *}\left(K^{i}\right)\right)} .
$$

The function $\phi^{\prime}\left(S_{\text {full }}^{i *}\left(K^{i}\right)\right)$ denotes the derivative of $\varphi(\cdot)$ with respect to the optimal investment strategy $S_{\text {full }}^{i^{*}}\left(K^{i}\right)$. The left-hand side of equality (11) represents the net value of the auctioneer's payoff at the time the investment is exercised. The right-hand side may be interpreted as the opportunity cost of exercising the option with payoff value equal to $S_{\text {full }}^{i *}\left(K^{i}\right)-K^{i}$.

The auctioneer's ex ante value (i.e., the auctioneer's value before the agents report their cost levels) is given by

$$
V_{\text {full }}^{P}(s)=E\left[\tilde{V}_{\text {full }}^{P}\left(s, K^{i}\right) \mid F_{0}^{S}\right]
$$

Note that the auctioneer's ex ante value in equation (12) increases in the number of auction participants $n$. The reason is that as the number of participants gets larger, the probability that the contract winner's cost level will be lower, also increases. A reduced cost level of the contract winner, increases the auctioneer's value from the auction.

When we later study effects of competition and asymmetric information, we will use the project owner's value under full information as a benchmark.

\section{The Agents' Reporting Behavior when they have Private Information}

The project owner finds an optimal contract using the revelation principle. In order to ensure that the agents report truthfully, the 
following first-order condition for the report $\hat{K}^{i}$ must be satisfied for each agent $i$ at the point where truth telling is optimal, i.e., where $\hat{K}^{i}=K^{i}$,

$$
\left.\frac{\partial v^{i}\left(s, K^{i} ; \hat{K}^{i}\right)}{\partial \hat{K}^{i}}\right|_{\hat{R}^{i}=K^{i}}=0
$$

Let now $v^{i}\left(s, K^{i}\right)$ be each agent $i$ 's value function when it is optimal to report truthfully. The value function of agent $i$ under truth telling can be written as

$$
\begin{aligned}
v^{i}\left(s, K^{i}\right)= & E\left[\frac{\phi(s)}{\phi\left(S^{i}(K)\right)}\left(X^{i}\left(S^{i}(K), K\right)-y^{i}(K) K^{i}\right) \mathrm{I}_{\left\{s<S^{i}(K)\right\}}\right. \\
& \left.+\left(X^{i}(s, K)-y^{i}(K) K^{i}\right) \mathrm{I}_{\left\{s \geq S^{i}(K)\right\}} \mid F_{0}^{S, K^{i}}\right]
\end{aligned}
$$

which is equal to equation (8) with the exception that the vector $\hat{K}$ is replaced by the vector $K$.

By the envelope theorem, the first-order condition in equation (13) is found as

$$
\frac{d v^{i}\left(s, K^{i}\right)}{d K^{i}}=E\left[-\frac{\phi(s)}{\phi\left(S^{i}(K)\right)} y^{i}(K) \mathrm{I}_{\left\{s<S^{i}(K)\right\}}-y^{i}(K) \mathrm{I}_{\left\{s \geq S^{i}(K)\right\}} \mid F_{0}^{S, K^{i}}\right] .
$$

The second-order condition for truth telling is given by

$$
\left.\frac{\partial^{2} v^{i}\left(s, K^{i} ; \hat{K}^{i}\right)}{\partial \hat{K}^{i 2}}\right|_{\hat{K}^{i}-K^{i}} \leq 0
$$

A corresponding proof in Mæland (2002) shows that the second-order condition is satisfied as long as the critical price for investment is increasing in the true investment cost.

Let $\theta^{i}\left(s, K^{-i}\right)$ be agent $i$ 's investment trigger when truth telling is the optimal strategy such that investment is made immediately when 
$\theta^{i}\left(s, K^{-i}\right) \geq K^{i}$, and postponed when $\theta^{i}\left(s, K^{-i}\right)<K^{i}$. Thus, $\theta^{i}$ is the inverse investment trigger of $S^{i}(\hat{K})$, and is restricted by $\theta^{i} \in[\underline{K}, \bar{K}]$. Integration of both sides of the first-order condition in equation (15) leads to the following expression of agent $i$ 's value of private information,

$$
\begin{gathered}
v^{i}\left(s, K^{i}\right)=E\left[\int_{K^{i}}^{\bar{K}} \frac{\phi(s)}{\phi\left(S^{i}\left(K^{-i}, u\right)\right)} y^{i}\left(K^{-i}, u\right) d u \mathrm{I}_{\left\{s<S^{i}(K)\right\}}+\left(\int_{K^{i}}^{\vartheta^{i}\left(s, K^{-i}\right)}\right.\right. \\
\left.\left.y^{i}\left(K^{-i}, u\right) d u+\int_{\theta\left(s, K^{-i}\right)}^{\bar{K}} \frac{\phi(s)}{\phi\left(S^{i}\left(K^{-i}, u\right)\right)} y^{i}\left(K^{-i}, u\right) d u\right) \mathrm{I}_{\left\{s \geq S^{i}(K)\right\}} \mid F_{0}^{S, K^{i}}\right] .
\end{gathered}
$$

In equation (17) we have formulated agent $i$ 's value of private information, excluding the unknown compensation function $X^{i}(\cdot)$. The situation in which there is only agent with private information, i.e., where $n=1$, corresponds to the principal-agent model in Mæland (2002). In this case $y^{i}(\cdot)=1$. When $n>1$ agent $i$ 's value in equation (17) is adjusted for the probability of winning the contract, $y^{i}(\cdot)$. Also, when $n>1$ the value of private information is stochastic as each agent does not observe the other agents' private information, whereas it is a deterministic function of $\mathrm{s}$ and $K^{i}$ if $n=1$.

\section{The Auctioneer's Optimization Problem}

In this section we solve the auctioneer's optimization problem, i.e., we choose the winner of the auction and find the optimal, implementable investment strategy. In order to do so we replace the compensation function, $X^{i}(\cdot)$, with an expression of known variables, using the relationship in equation (14). Then the auctioneer's optimization problem in equation (9) is formulated as

$$
V^{P}(s)=\sup _{S^{i}(\cdot), y^{u}(\cdot)} E\left[\sum _ { i = 1 } ^ { n } \left\{\frac{\phi(s)}{\phi\left(S^{i}(K)\right)} y^{i}(K)\left(S^{i}(K)-K^{i}\right) \mathrm{I}_{\left\{s<S^{i}(K)\right\}}\right.\right.
$$




$$
\left.+y^{i}(K)\left(s-K^{i}\right) \mathrm{I}_{\left\{s \geq S^{i}(K)\right\}}-v^{i}\left(s, K^{i}\right) \mid F_{0}^{S}\right],
$$

where agent $i$ 's value $v^{i}\left(s, K^{i}\right)$ is given by equation (17). The auctioneer's value in equation (18) is the value when the privately informed agents have no incentives not to reveal their information. Thus, the expected compensation for each agent $i$ consists of the sum of the true investment $\operatorname{cost} K^{i}$, adjusted for the probability of being the contract winner, $y^{i}(K)$, and the value of agent $i$ 's participation in the auction, $v^{i}\left(s, K^{i}\right)$.

Observe that the optimization problem could be simplified if the trigger function $S^{i}$ were dependent on agent $i$ 's cost level $K^{i}$, only, instead of the vector of all costs, $K$. The reason is that if $S^{i}\left(K^{i}\right)$ equals $S^{\mathrm{i}}(K)$ we can optimize the auctioneer's value with respect to each agent $i$ separately. In appendix A, it is shown that this is the optimal solution indeed, i.e., $S^{i *}\left(K^{i}\right)=S^{i *}(K)$, where $S^{i *}(\cdot)$ is defined as the optimal investment trigger of agent $i$. The idea of this simplification is based on Laffont and Tirole (1987), where a similar argument is used to show that a random incentive scheme is not optimal.

The auctioneer's value function depends linearly on the control variable $y^{i}(K)$, indicating whether agent $i$ is the winner of the contract or not. Thus, we can substitute $y^{i}(K)$ by defining $Y^{i}\left(K^{i}\right)=E\left[y^{i}(K) \mid F_{0}^{S, K^{i}}\right]$ in the optimization problem in equation (18).

Define $\hat{V}^{P}(s)=\sup _{S^{i}(\cdot), y^{i}(\cdot)} \hat{v}^{P}(s)$ as the auctioneer's optimization problem when $S^{i}(K)$ is replaced by $S^{i}\left(K^{i}\right)$. For given $y^{i}(\cdot)$, and hence for given $Y^{i}(\cdot)$, the auctioneer's optimization problem (derived in appendix $\mathrm{B})$, is given by

$$
\begin{gathered}
\hat{V}^{P}(s)=\sup _{S^{i}(\cdot)} \sum_{i=1}^{n}\left\{\int _ { \underline { K } } ^ { \overline { K } } \left[\frac{\phi(s)}{\phi\left(S^{i}\left(K^{i}\right)\right)} Y^{i}\left(K^{i}\right)\left(S^{i}(K)-K^{i}-\frac{F\left(K^{i}\right)}{f\left(K^{i}\right)}\right)\right.\right. \\
\left.\left.\mathrm{I}_{\left\{s<S^{i}\left(K^{i}\right)\right\}}+\left(Y^{i}\left(K^{i}\right)\left(s-K^{i}-\frac{F\left(K^{i}\right)}{f\left(K^{i}\right)}\right)\right) \mathrm{I}_{\left\{s \geq S^{i}\left(K^{i}\right)\right\}}\right] f\left(K^{i}\right) d K^{i}\right\}
\end{gathered}
$$

Observe that we now can separate the problem of finding the optimal critical price $S^{i *}\left(K^{i}\right)$, and the problem of choosing a winner of the contract. The auctioneer's optimization problem is similar to the 
problem of exercising an American call option, with exercise price $K^{i}$ $+F\left(K^{i}\right) / f\left(K^{i}\right)$. The term $F\left(K^{i}\right) / f\left(K^{i}\right)$ is called the inverse hazard rate, and represents the probability that agent $i$ 's investment cost is lower than or equal to $K^{i}$, divided by the probability density of $K^{i}$. In our model the ratio can be interpreted as an "inefficiency cost" due to agent $i$ 's private information.

Optimizing the auctioneer's simplified problem in (19) with respect to $S^{i}\left(K^{i}\right)$ results in an optimal investment strategy, $S^{i *}\left(K^{i}\right)$, given by

$$
S^{i *}\left(K^{i}\right)-K^{i}-\frac{F\left(K^{i}\right)}{f\left(K^{i}\right)}=\frac{\phi\left(S^{i *}\left(K^{i}\right)\right)}{\phi^{\prime}\left(S^{i *}\left(K^{i}\right)\right)}
$$

with lower limit $S^{i *}(\underline{K})$ and upper limit $S^{i *}(\bar{K})$. If we compare the optimal investment strategy under private information, in (20), and full information, in (11), we find that the auctioneer's payoff at the investment side, given by the left-hand side of the equations, is reduced by the fraction $F\left(K^{i}\right) / f\left(K^{i}\right)$ under private information. Thus, the fraction $F\left(K^{i}\right) / f\left(K^{i}\right)$ can be interpreted as an "efficiency cost" due to private information. It can be shown that the optimal investment strategy $S^{i *}$ is higher than it would be if the project owner had full information about the investment cost, i.e., $S^{i *}\left(K^{i}\right) \geq S_{\text {full }}^{i *}\left(K^{i}\right)$, where $S_{\text {full }}^{i *}\left(K^{i}\right)$ is given in equation (11). This means that when the asset value $s$ is between the optimal investment strategies under full and asymmetric information, respectively, asymmetric information leads to under-investment. For a proof, see Mæland (2002).

Since the control variable $y^{i}(K)$ is linear in the auctioneer's problem of finding the investment strategy of agent $i$, we choose an optimal $y^{i *}(K)$ such that

$$
y^{i *}(K)= \begin{cases}1 & \text { if } \quad K^{i}<\min _{j \neq i} K^{j} \\ 0 & \text { if } \quad K^{i}>\min _{j \neq i} K^{j} .\end{cases}
$$

Thus, the agent with the lowest cost wins the contract. If $K^{i}=\min _{j \neq 1} K^{j}$, the auctioneer is indifferent between agents $i$ and $j$.

Note that the optimal investment strategy is independent of the number of privately informed agents $n$, which means that the efficiency is not improved when competition is introduced. However, based on ex ante information, the winner of the contract probably has a lower 
investment cost when $n>1$ than in the situation where there is only one agent with private information. Therefore, for $n>1$ the investment will probably take place at a lower cost then for $n=1$. Moreover, if the number of competing agents gets large, the winner's cost level gets close to the lowest possible cost, $\underline{K}$. When the winner's cost level in probability converges to $\underline{K}$, the cumulative distribution $F(\cdot)$ converges to zero, which leads to no inefficiency in the investment strategy. These effects are illustrated through an example in section VII.

\section{Implementation of the Contract}

Let $\theta^{i *}$ be the optimal trigger for investment, $\theta^{i *} \in[\underline{K}, \bar{K}]$. Combining equations (17), (20) and (21), we find that agent $i$ 's value of private information can be expressed as

$$
V^{i}\left(s ; K^{i}\right)=\left\{\begin{array}{lr}
\int_{K^{i}}^{\bar{K}} \frac{\phi(s)}{\phi\left(S^{i *}(u)\right)} Y^{i *}(u) d u & \text { if } s<S^{i *}\left(K^{i}\right) \\
\int_{K^{i}}^{\theta^{i *}(s)} Y^{i *}(u) d u+\int_{\theta^{i *}(s)}^{\bar{K}} \frac{\phi(s)}{\phi\left(S^{i *}(u)\right)} Y^{i *}(u) d u \text { if } s \geq S^{i *}\left(K^{i}\right)
\end{array}\right.
$$

Equation (22) represents each agent's ex ante value of participating in the auction.

Hence, agent $i$ 's optimal value of the expected compensation $X^{i *}\left(s, K^{i}\right)$ is given by

$$
X^{i *}\left(s, K^{i}\right)=\left\{\begin{array}{lr}
0 & \text { if } s<S^{i *}(K) \\
K^{i} Y^{i *}\left(K^{i}\right)+\int_{K^{i}}^{\theta^{* *}(s)} Y^{i *}(u) d u+\int_{\theta^{i *}(s)}^{\bar{K}} \frac{\phi(s)}{\phi\left(S^{i *}(u)\right)} Y^{i *}(u) d u \\
K^{i} Y^{i *}\left(K^{i}\right)+\int_{K^{i}}^{\bar{K}} Y^{i *}(u) d u & \text { if } S^{i *}\left(K^{i}\right) \leq s<S^{i *}(\bar{K})
\end{array}\right.
$$


Note that equation (23) represents the ex ante expected compensation of each agent participating in the auction. In the expression of the optimal compensation function, each agent's strategy is optimal based on expected quantities, i.e., the strategy depends on $Y^{i *}\left(K^{i}\right)=$ $E\left[y^{i *}(K) \mid F_{0}^{S, K^{i}}\right]$ and $S^{i *}\left(K^{i}\right)=E\left[S^{i *}(K) \mathrm{I}_{\left\{y^{* *}(K)=1\right\}} \mid F_{0}^{S, K^{i}}\right]$. We need to find an implementable compensation function of the winner of the contract. In order to do so, we construct a dominant strategy auction where each agent has a reporting strategy that is optimal for any reports by the other agents ${ }^{7}$ in which each agent has a reporting strategy that is optimal for any reports by the other agents. We formulate a second-price sealed-bid private values auction (or a Vickrey auction) that implements the optimal investment strategy and selects the agent with the lowest cost. We denote the implementable compensation function $\tilde{X}^{i}$, and its value is given by

$$
\tilde{X}^{i}(s, K)= \begin{cases}\vartheta^{i^{*}}(s)+\int_{\vartheta^{i^{*}}(s)}^{\bar{K}} \frac{\phi(s)}{\phi\left(S^{i^{*}}(u)\right)} d u & \text { if } S^{i^{*}}\left(K^{i}\right) \leq s<S^{i^{*}}\left(K^{j}\right) \\ K^{j} & \text { if } s \geq S^{i^{*}}\left(K^{j}\right)\end{cases}
$$

if $K^{i}=\min _{h} K^{h}$ and $K^{j}=\min _{h \neq i} K^{h}$. If $s<S^{i *}\left(K^{i}\right)$, then $\tilde{X}^{i}(s, K)$ $=0$. Thus, $\tilde{X}^{i}$ is the optimal compensation to agent $i$, given that agent $i$ is the winner of the contract. In appendix $\mathrm{C}$ it is shown that each agent's expected value of the compensation function in equation (24), $E\left[\tilde{X}^{i}(s, K) \mid F_{0}^{S, K^{i}}\right]$, equals the value in equation (23), i.e., $X^{i *}\left(s, K^{i}\right)=E\left[\tilde{X}^{i}(s, K) \mid F_{0}^{S, K^{i}}\right]$.

The optimal compensation function in equation (24) represents an implementable and incentive compatible contract, i.e., it ensures that it is optimal for the contract winner to follow the optimal investment strategy in equation (20): When $s<S^{i *}\left(K^{i}\right)$ the contract winner postpones the option to invest until the point in time when the asset value, $s$, reaches $S^{i *}\left(K^{i}\right)$. It is optimal for him to invest immediately if $s \geq S^{i *}\left(K^{i}\right)$. It can be shown that the winner of the contract will never reject the contract as the value of participating always is positive,

7. A dominant strategy auction is an auction in which each agent has a strategy that is optimal for any strategies of its competitors. 
confer Mæland (2002). Moreover, the project owner's and the contract winner's respective values are the same whether it is the project owner who makes the investment decision based on the contract winner's cost report, or the investment decision is delegated to the contract winner. The reason is that the investment strategy $S^{i *}$ is a one-to-one function of the privately observed parameter $K^{i}$. This result corresponds to a more general result in Melumad and Reichelstein (1989).

Equation (24) shows that when agent $i$ wins the contract, the agent's compensation equals the value of his private information when the distribution is truncated at $K^{j}$. Thus, competition for the best agent amounts to a truncation of the interval $(\underline{K}, \bar{K})$ to $\left(\underline{K}, K^{j}\right)$, where $K^{j}$ is the second-lowest cost report.

Note that the optimal compensation function in equation (24) equals the optimal compensation function for the case when there is only one agent with private information, with the exception that the truncation is changed from $\bar{K}$ to the second-lowest report $K^{j}$. Thus, the optimal compensation to the contract winner is lower under competition than under no competition, as long as $\bar{K}$ is higher than the cost of the agent with the second-lowest cost.

\section{Numerical Illustration: Effects of Competition and Private Information}

In order to illustrate our results we assume that the value of the asset in place is driven by a geometric Brownian motion,

$$
d S_{t}=\left(r-\delta_{S}\right) S_{t} d t+\sigma_{S} S_{t} d B_{t}, \quad s \equiv S_{0},
$$

where $\delta_{S}$ denotes the convenience yield per year and $\sigma_{S}$ represents the yearly volatility. For simplicity, the unobservable investment cost parameter $K^{i}$ is assumed to be uniformly distributed, with lower and upper limits denoted $\underline{K}$ and $\bar{K}$, respectively. The probability density of the uniformly distributed investment cost is given by $f\left(K^{i}\right)=1 /(\bar{K}-\underline{K})$. As the investment cost is uniformly distributed, each agent $i$ 's probability of being the contract winner equals

$$
Y^{i *}\left(K^{i}\right)=\left[\frac{\bar{K}-K^{i}}{\bar{K}-\underline{K}}\right]^{n-1} .
$$


When the asset value $S_{t}$ is driven by a geometric Brownian process, we find that $\varphi(s)=s^{\beta}$, where

$$
\beta=\frac{1}{\sigma_{S}}\left[\frac{1}{2} \sigma_{S}^{2}-\left(r-\delta_{S}\right)+\sqrt{\left(\left(r-\delta_{S}\right)-\frac{1}{2} \sigma_{S}^{2}\right)^{2}+2 r \sigma_{S}^{2}}\right]>1 .
$$

Thus, the net present value of receiving 1 at the optimal stopping time is given by $\left(s / S^{i}\right)^{\beta}$ when $s<S^{i}$.

Furthermore, we find that the optimal investment strategy is given by

$$
S^{i *}\left(K^{i}\right)= \begin{cases}\underline{K} \frac{\beta}{\beta-1} & \text { if } s<\underline{K} \frac{\beta}{\beta-1} \\ \left(2 K^{i}-\underline{K}\right) \frac{\beta}{\beta-1} & \text { if } \underline{\mathrm{K}} \frac{\beta}{\beta-1} \leq s<(2 \bar{K}-\underline{K}) \frac{\beta}{\beta-1}(2) \\ (2 \bar{K}-\underline{\underline{K}}) \frac{\beta}{\beta-1} & \text { if } s \geq(2 \bar{K}-\underline{K}) \frac{\beta}{\beta-1}\end{cases}
$$

and that the inverse, optimal investment strategy is represented by

$$
v^{i *}(s)= \begin{cases}\underline{K} & \text { if } s \frac{\beta-1}{\beta}<\underline{K} \\ \frac{1}{2}\left(s \frac{\beta-1}{\beta}+\underline{K}\right) & \text { if } \underline{\mathrm{K}} \leq \frac{1}{2}\left(s \frac{\beta-1}{\beta}+\underline{K}\right)<\bar{K} \\ \overline{\mathrm{K}} & \text { if } \frac{1}{2}\left(s \frac{\beta-1}{\beta}+\underline{K}\right) \geq \bar{K}\end{cases}
$$

In the case of full information about the investment cost $K^{i}$, the optimal investment strategy $S_{\text {full }}^{i *}\left(K^{i}\right)$ equals

$$
S_{\text {full }}^{i *}\left(K^{i}\right)=K^{i} \frac{\beta}{\beta-1},
$$

for $K^{i} \in[\underline{K}, \bar{K}]$. Thus, asymmetric information increases the critical price by $\left(K^{i}-\underline{K}\right) \beta /(\beta-1)$ for $S^{i *}\left(K^{i}\right) \in\left[S^{i *}(\underline{K}), S^{i *}(\bar{K})\right]$.

Assume now that agent $i$ is the winner of the contract. The 
compensation function of the contract winner, as given by equation (24), equals

$$
\tilde{X}^{i}(s, K)=\left\{\begin{array}{ll}
\frac{1}{2}\left[s+\underline{K}-\left(\frac{s}{S^{i *}\left(K^{j}\right)}\right)^{\beta} \frac{2 K^{j}-\underline{K}}{\beta-1}\right] \\
K^{j} & \text { if } S^{i *}\left(K^{i}\right) \leq s<S^{i *}\left(K^{j}\right)
\end{array},\right.
$$

where $K^{j}$ is the cost of the agent with the second-lowest cost report.

Let $\tilde{V}^{P}$ represent the auctioneer's value after contracting, where $V^{P}(s)=E\left[\tilde{V}^{P}(s, K) \mid F_{0}^{S}\right]$. Thus, we interpret $\tilde{V}^{P}$ as the auctioneer's value when he has received the cost reports, and is committed to the specified contract. Computation of the auctioneer's ex post value leads to

$$
\tilde{V}^{P}(s, K)=\left\{\begin{array}{lr}
\left(\frac{s}{S^{i *}\left(K^{i}\right)}\right)^{\beta}\left(S^{i *}\left(K^{i}\right)-\tilde{X}^{i}\left(S^{i *}\left(K^{i}\right), K\right)\right) & \text { if } s<S^{i *}\left(K^{i}\right) \\
s-\tilde{X}^{i}(s, K) & \text { if } s \geq S^{i *}\left(K^{i}\right)
\end{array}\right.
$$

Note that under full information, $\tilde{X}^{i}=K^{i}$. Hence, in this case the auctioneer's ex post value is similar to a perpetual American call option with, where $S^{i *}$ is the asset value at the investment time, and $K^{i}$ is the strike price.

Under asymmetric information, each agent's value of private information equals

$$
V^{i}\left(s, K^{i}\right)=\left\{\begin{array}{lr}
\int_{K^{i}}^{\bar{K}}\left(\frac{s}{S^{i *}(u)}\right)^{\beta} Y^{i *}(u) d u & \text { if } s<S^{i *}\left(K^{i}\right) \\
\int_{K^{i}}^{\theta^{i *}(s)} Y^{i}(u) d u+\int_{\theta^{i *}(s)}^{\bar{K}}\left(\frac{s}{S^{i *}(u)}\right)^{\beta} Y^{i}(u) d u & \text { if } S^{i *}\left(K^{i}\right) \leq s<S^{i *}(\bar{K}) \\
\int_{K^{i}}^{\bar{K}} Y^{i}(u) d u & \text { if } s \geq S^{i *}(\bar{K})
\end{array}\right.
$$

The special case of a geometric Brownian process and uniformly 
distributed investment cost are illustrated numerically below, using the following base case parameter values:

The investment cost: $K^{i}=100$

The lower limit of the investment cost: $\underline{K}=50$

The upper limit of the investment cost: $\bar{K}=200$

The risk-free rate of interest: $r=0.05$

The convenience yield rate: $\delta_{S}=0.03$

Volatility of asset in place: $\sigma_{S}=0.10$

The parameter values lead to the following pre-computed quantities in the base case:

The probability density: $f\left(K^{i}\right)=1 / 150$

The probability distribution: $F\left(K^{i}\right)=50 / 150$

The inverse hazard rate: $F\left(K^{i}\right) / f\left(K^{i}\right)=50$

The positive root satisfying the ODE: $\beta=2$

The investment trigger, full information: $S_{\text {full }}^{i *}\left(K^{i}\right)=200$

The inv. trigger, full information, $K^{i}=\bar{K}: S_{\text {full }}^{i *}(\bar{K})=400$

The investment trigger, asymmetric information: $S^{i *}\left(K^{i}\right)=300$

The investment trigger, asym. info., $K^{i}=\bar{K}: S^{i *}(\bar{K})=700$

The optimal investment strategies under asymmetric information, $\theta^{i *}$, and full information, $\theta_{\text {full }}^{i *}$, respectively, are presented in figure 1 . In both cases the optimal investment strategy is a linear function of the asset value $s$, as long as the functions $\theta^{i *}$ and $\theta_{\text {full }}^{i *}$ are between $\underline{K}=50$ and $\bar{K}=200$. The optimal investment strategy under asymmetric information leads to underinvestment compared to the optimal strategy under full information. For instance, if the asset value, $s$, equals 300 it is optimal to invest immediately when the true investment cost $K^{i}$ is lower than 100 under asymmetric information, and when $K^{i}$ is lower than 150 in the case of full information. Under asymmetric information, $\theta^{i *}$ is constant when $s<100$ and $s \geq 700$, which is equal to the lower and upper limits for $S^{i *}$, respectively. 


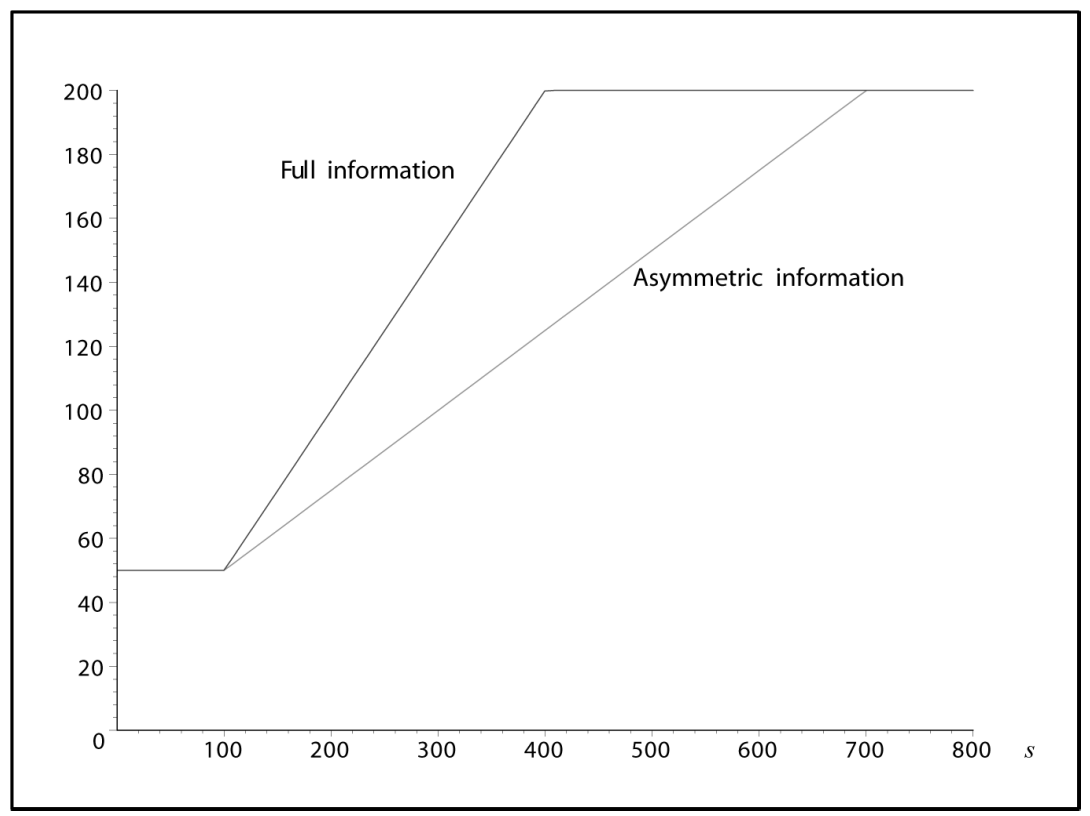

FIGURE 1.- The optimal investment strategies under asymmetric and full information, $\theta^{i *}$ and $\theta_{\text {full }}^{i *}$, respectively, as functions of the asset value $s$.

Analogously, under full information $\theta_{\text {full }}^{i *}$ is constant when $s<100$ and $s \geq 400$. Note that the optimal investment strategies under full and asymmetric information, respectively, are identical for $s<100$ and $s \geq$ 400.

The auctioneer's ex ante values under asymmetric and full information, $V^{P}$ and $V_{\text {full }}^{P}$, are illustrated in figure 2 . The lower and the second-lower curves represent the auctioneer's values under asymmetric and full information when four agents participate in the auction, whereas the upper and the second-upper curve give the respective values under full and asymmetric information when only one agent has private information. Under both full information and asymmetric information the auctioneer's value increases as the number of participating agents increases. The reason in the full information case is that as the number of competitors increases, the probability that the contract winner has a lower cost increases, too. The same effect applies under asymmetric information. However, since the contract winner is paid according to the cost of the agent with the second-lowest cost report, we have an 


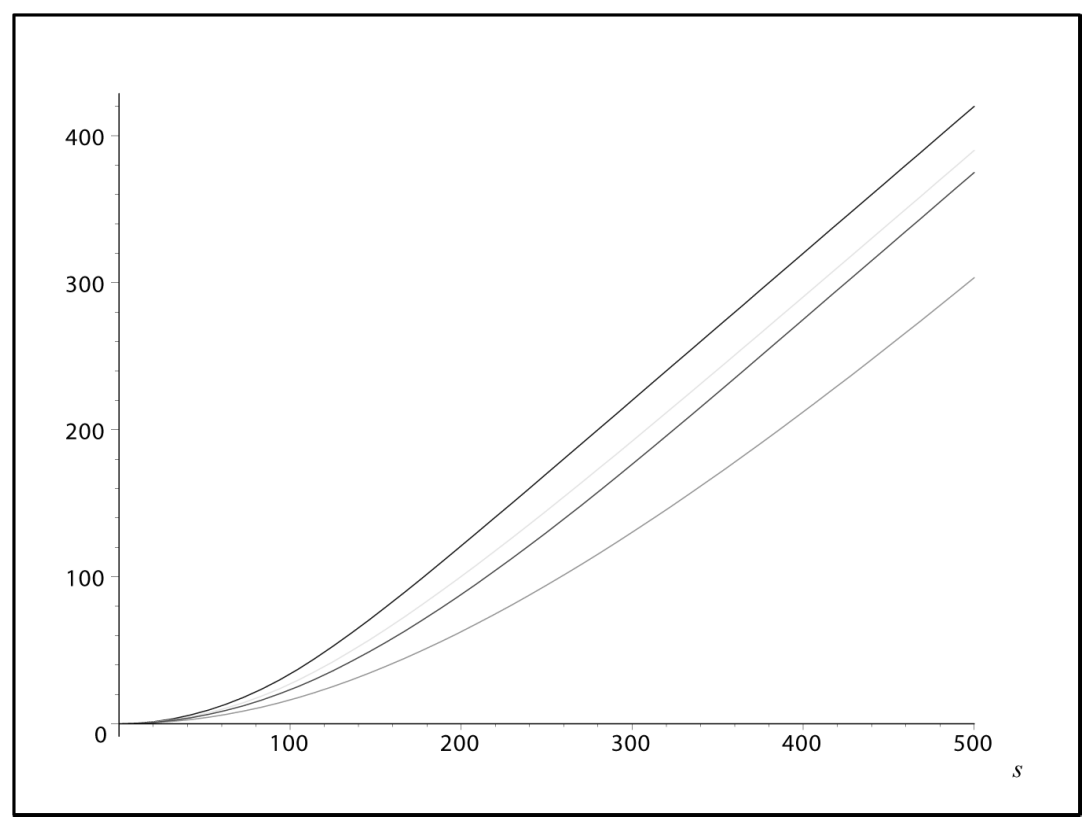

FIGURE 2.- The auctioneer's ex ante value from the auction, as functions of the asset value $s$. The two upper curves show the auctioneer's value under full and asymmetric information, $V^{P}$ and $V_{\text {full }}^{P}$, respectively, when $n=4$. Analogously, the two lower curves represent the values under full and asymmetric information when $n=1$.

additional effect under asymmetric information: as the number of privately informed agents increases, the probability that the second-lowest cost report is reduced, will be higher. When the second-lowest cost report decreases, the compensation to the contract winner decreases, too, leading to a higher value for the auctioneer. Thus, figure 2 shows that the difference between the auctioneer's value under full and asymmetric information decreases in the number of competitors, which means that the inefficiency due to private information will be less severe as the number of privately informed agents gets larger.

Figure 3 illustrates each agent's value of participating in the auction (i.e., each agent's value of private information). In the figure we draw four curves representing the value when there is no competition $(n=1)$, and when there are two, four and six competitors, respectively. As the number of competitors increases, each agent's value falls rapidly. In the 


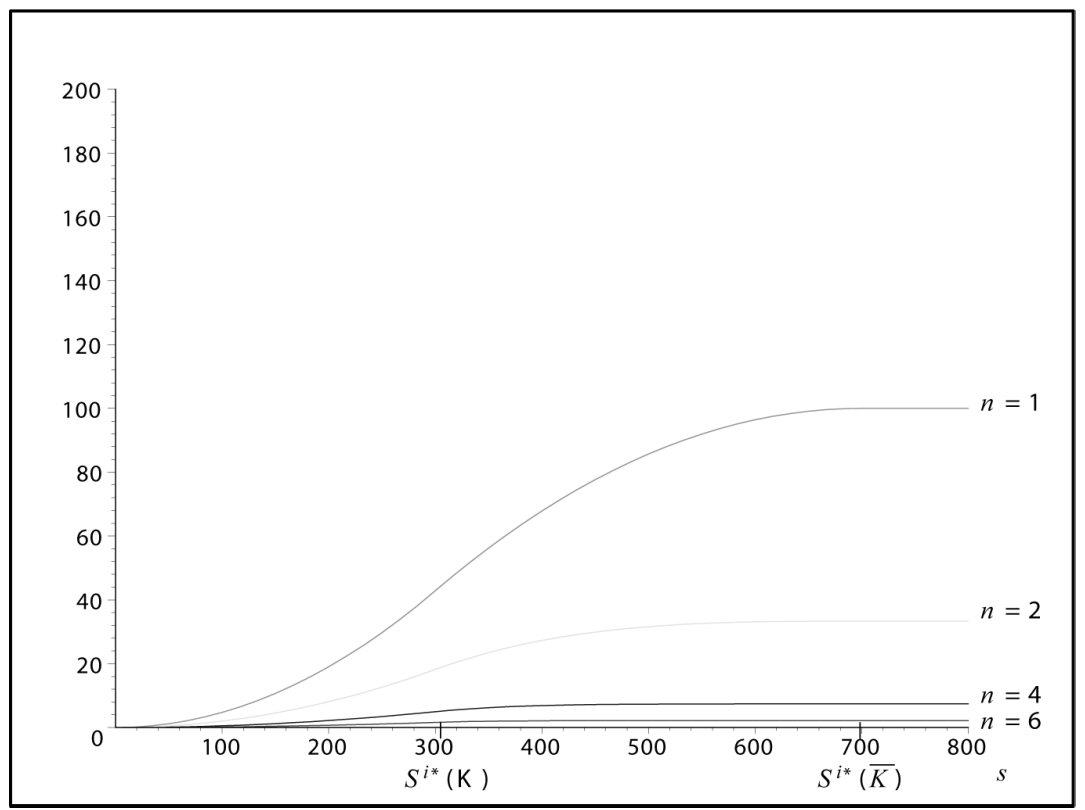

FIGURE 3.- Each agent's value $V^{i}$ as a function of the asset value $s$. The number of competitors is represented by $n$.

example, the winner's value falls by about two thirds when we go from no competition to two competitors. When there are six competitors the value of each auction participant is close to zero.

In figure 4 the winner's compensation function $\tilde{X}^{i}$ is drawn for different levels of the second-lowest cost report $K^{j}$. We assume that agent $i$ is the winner of the contract, and that agent $j$ has the second-lowest cost report. In the case in which the cost of the agent with the second-lowest report equals 200, the winner's compensation is equal to the compensation when we have no competition. The reason is that agent $j$ 's cost level coincide with the upper level cost $\bar{K}$. As agent $j$ 's cost level gets closer to the winner's investment cost $K^{i}=100$, the value of the agent's private information decreases. Moreover, as agent $j$ 's cost level decreases, the interval where the compensation is independent of the asset value s gets larger. This is the effect from reducing the possible cost reports from $[\underline{K}, \bar{K}]$ to $\left[\underline{K}, K^{j}\right]$. In the limiting case, where $K^{j}=$ 100 , the winner's value of the contract is zero, as the winner only obtains a compensation equal to his cost level for all asset values $s$.

Figure 5 illustrates the auctioneer's ex post value of the contract, 


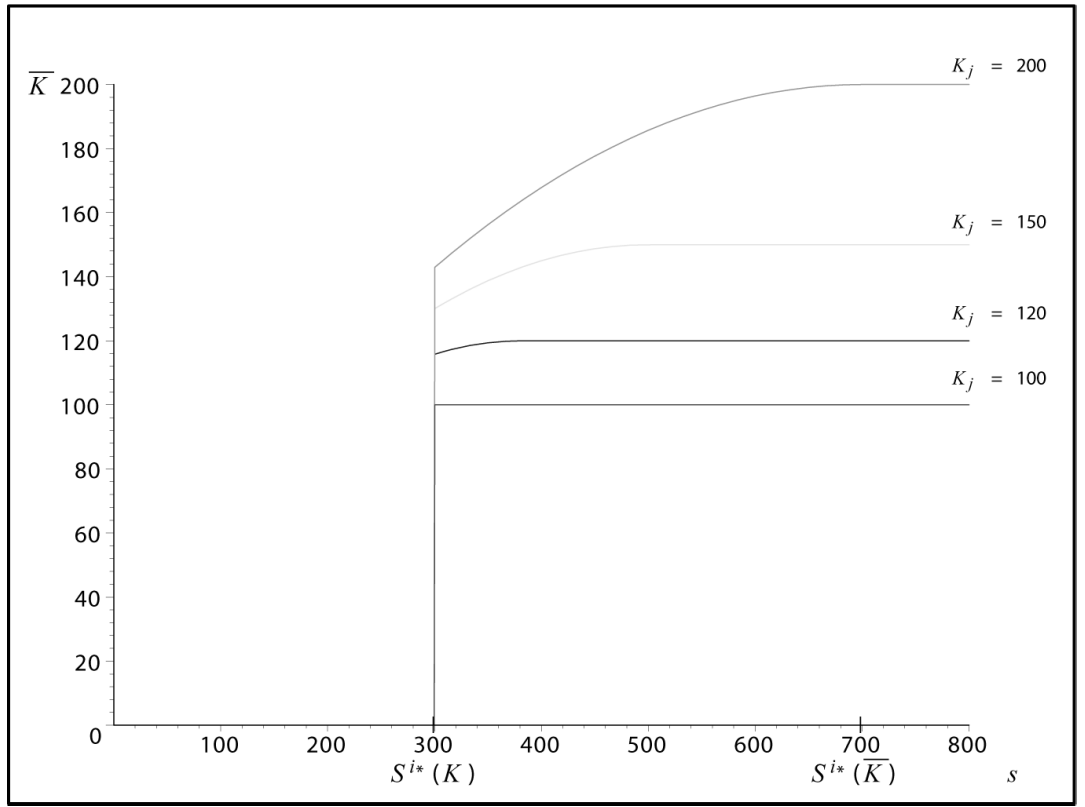

FIGURE 4.- The compensation $\tilde{X}^{i}$ as a function of the asset value $s$, for different values of second-lowest cost report $K^{j}$. The contract winner's investment cost is $K^{i}=100$.

$\tilde{V}^{P}$. The function $\tilde{V}^{P}$ is defined as the auctioneer's value for a given cost level of the contract winner, $K^{i}$, and for the second-lowest cost report, $K^{j}$. In figure 5 the upper curve corresponds to the full information case. The lowest curve represents the value when the second-lowest cost report, $K^{j}$, equals the upper cost level, $\bar{K}=200$. Note that this case is identical to a situation in which only one agent has private information. Thus, the lower curve is identical to the auctioneer's value under asymmetric information in the case of no competition. The second-lower curve and the second-upper curve are the auctioneer's values when the second-lowest cost reports are equal to 150 and 100 , respectively. In the limiting case where the second-lowest cost report equals 100, the contract winner's value of private information is zero, since both the compensation and the investment cost will be 100. However, even when the winner's value is zero, the optimal investment strategy under asymmetric information is not efficient as long as the winner's cost is above the lower limit $\underline{K}$. The effect is illustrated in figure 5: When the second lowest cost report 


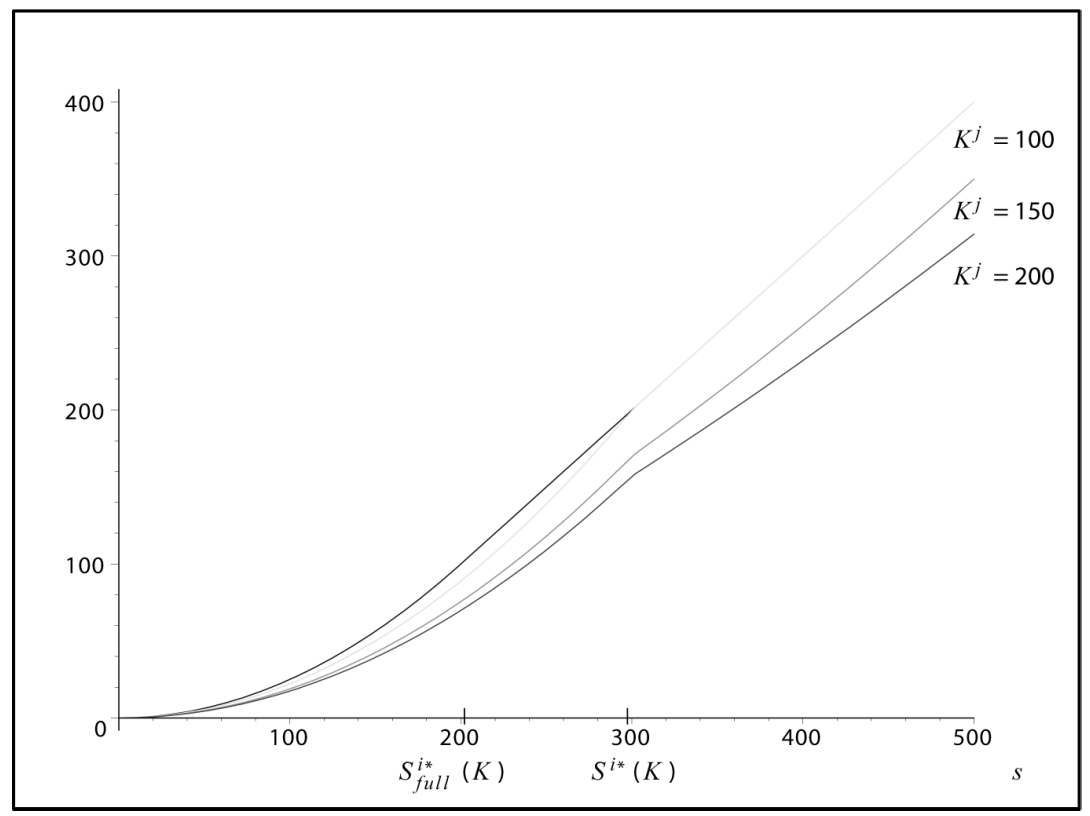

FIGURE 5.- The auctioneer's ex post value under asymmetric information, $\tilde{V}^{P}$, and under full information, $V_{\text {full }}^{P}$, as functions of the asset value $s$. The contract winner's investment cost is $K^{i}=100$. The upper curve is the auctioneer's ex post value under full information. The three other curves represent the auctioneer's value under asymmetric information, for different values of the second-lowest cost report, $K^{j}$.

equals 100 , the upper and the second upper curves coincides with the value under full information only in the interval where it is optimal to invest immediately, i.e., when $s \geq S^{i^{*}}\left(K^{i}\right)=300$. For $s<S^{i^{*}}\left(K^{i}\right)$ there is a difference between the full information value and the auctioneer's value under asymmetric information, as asymmetric information in this interval implies delayed investment.

\section{Concluding Remarks}

In this paper we have studied effects of private information about the costs of exercising a real option. We assumed that $n$ agents compete about winning the contract of managing an investment project, and the problem is analyzed in a Vickrey auction model. Each agent 
participating in the auction has (perfect) private information about his own costs, but he does not observe the competitors' cost levels. Corresponding to results for Vickrey auctions, we have found that the winner of the contract is the agent with the lowest cost, and his compensation is based on the investment cost of the agent with the second-lowest cost.

The model discussed in this paper is an extension of the principal-agent model in Mæland (2002) to the case of $n$ agents with private information. Similarly to the solution of the principal-agent model, optimal contracts are found using direct, truthful mechanisms. We have found that private information may lead to under-investment. Moreover, a result is that the optimal strategy function is independent of the number of privately informed agents. However, competition results in a lower compensation for the winning agent under competition than in the case of only one agent, leading to a higher project value for the owner of the investment project.

Accepted by: Prof. L. Trigeorgis, Guest Editor, April 2007

Prof. P. Theodossiou, Editor-in-Chief, April 2007

\section{Appendix}

\section{A. Properties of the Optimal Investment Strategy}

In this section we show that in optimum we have $S^{i *}(K)=S^{i *}\left(K^{i}\right)$.

Suppose that agent $i$ is the winner of the contract, i.e., $y^{i}(K)=1$. Define agent $i$ 's expected critical price as $S^{i}\left(K^{i}\right)=E\left[S^{i}(K)\right.$ $\left.\mathrm{I}_{\left\{y^{i}(K)=1\right\}} \mid F_{0}^{S, K^{i}}\right]$. For $s<S^{i}(K)$, the auctioneer's value if agent $i$ wins the contract can be written as (from (18))

$$
\begin{gathered}
E\left[\frac{\phi(s)}{\phi\left(S^{i}(K)\right)}\left(S^{i}(K)-K^{i}\right) \mathrm{I}_{\left\{s<S^{i}(K)\right\}}+\left(s-K^{i}\right) \mathrm{I}_{\left\{s \geq S^{i}(K)\right\}}\right. \\
\left.-v^{i}\left(s, K^{i}\right) \mid F_{0}^{S}\right] .
\end{gathered}
$$

Observe that, by Jensen's inequality, 


$$
E\left[\phi\left(S^{i}(K)\right) \mathrm{I}_{\left\{y^{i}(K)=1\right\}} \mid F_{0}^{S}\right] \geq \phi\left(S^{i}\left(K^{i}\right)\right)
$$

under the assumption that $\phi(\cdot)$ is a convex function and

$$
\phi\left(S^{i}\left(K^{i}\right)\right) \equiv \phi\left(E\left[S^{i}(K) \mathrm{I}_{\left\{y^{i}(K)=1\right\}} \mid F_{0}^{S}\right]\right)
$$

This implies that

$$
\begin{gathered}
\frac{\phi(s)}{\phi\left(S^{i}\left(K^{i}\right)\right)}\left(S^{i}\left(K^{i}\right)-K^{i}\right) \mathrm{I}_{\left\{s<S^{i}(K)\right\}}-v^{i}\left(s, K^{i}\right) \\
\geq E\left[\left(\frac{\phi(s)}{\phi\left(S^{i}(K)\right)}\left(S^{i}(K)-K^{i}\right)-v^{i}\left(s, K^{i}\right)\right) \mathrm{I}_{\left\{s<S^{i}(K)\right\}} \mid F_{0}^{S}\right] .
\end{gathered}
$$

Thus, the auctioneer's value function can be replaced by a larger quantity, by substituting $S^{i}(K)$ by $S^{i}\left(K^{i}\right)$.

\section{B. The Auctioneer's Simplified Optimization Problem}

Define $\hat{\mathcal{v}}^{P}$ as the auctioneer's arbitrary value function when $S^{i}\left(K^{i}\right)=$ $S^{i}(K)$. Replace the investment triggers $S^{i}(K)$ by $S^{i}\left(K^{i}\right)$, in the principal's value function specified by equation (18), leading to

$$
\begin{aligned}
\hat{v}^{P}(s) & =E\left[\sum _ { i = 1 } ^ { n } \left\{\frac{\phi(s)}{\phi\left(S^{i}\left(K^{i}\right)\right)} y^{i}(K)\left(S^{i}\left(K^{i}\right)-K^{i}\right) \mathrm{I}_{\left\{s<S^{i}\left(K^{i}\right)\right\}}\right.\right. \\
& \left.\left.+y^{i}(K)\left(s-K^{i}\right) \mathrm{I}_{\left\{s \geq S^{i}\left(K^{i}\right)\right\}}-v^{i}\left(s, K^{i}\right)\right\} \mid F_{0}^{S}\right] .
\end{aligned}
$$

Furthermore, conditional expectations yield

$$
\hat{\mathcal{\nu}}^{P}(s)=E\left[E \left[\sum _ { i = 1 } ^ { n } \left\{\frac{\phi(s)}{\phi\left(S^{i}\left(K^{i}\right)\right)} y^{i}(K)\left(S^{i}\left(K^{i}\right)-K^{i}\right) \mathrm{I}_{\left\{s<S^{i}\left(K^{i}\right)\right\}}\right.\right.\right.
$$




$$
\left.\left.\left.+y^{i}(K)\left(s-K^{i}\right) I_{\left\{s \geq S^{i}\left(K^{i}\right)\right\}}-v^{i}\left(s, K^{i}\right)\right\} \mid F_{0}^{S, K^{i}}\right] \mid F_{0}^{S}\right]
$$

which, by exploiting the definition $Y^{i}\left(K^{i}\right)=E\left[y^{i}(K) \mid F_{0}^{S, K^{i}}\right]$, can be written as

$$
\begin{gathered}
\hat{\mathcal{v}}^{P}(s)=E\left[E \left[\sum _ { i = 1 } ^ { n } \left\{\frac{\phi(s)}{\phi\left(S^{i}\left(K^{i}\right)\right)} Y^{i}\left(K^{i}\right)\left(S^{i}\left(K^{i}\right)-K^{i}\right) \mathrm{I}_{\left\{s<S^{i}\left(K^{i}\right)\right\}}\right.\right.\right. \\
\left.\left.\left.+Y^{i}\left(K^{i}\right)\left(s-K^{i}\right) \mathrm{I}_{\left\{s \geq S^{i}\left(K^{i}\right)\right\}}-v^{i}\left(s, K^{i}\right)\right\} \mid F_{0}^{S, K^{i}}\right] \mid F_{0}^{S}\right] .
\end{gathered}
$$

Each agent's "contribution" to the auctioneer's value is an expression that depends only on each agent $i$ 's report $K^{i}$ (i.e., the direct mechanism is not stochastic) which means that the outer expectation operator is superfluous. Hence,

$$
\begin{aligned}
\hat{\mathcal{v}}^{P}(s) & =\sum_{i=1}^{n} E\left[\left\{\frac{\phi(s)}{\phi\left(S^{i}\left(K^{i}\right)\right)} Y^{i}\left(K^{i}\right)\left(S^{i}\left(K^{i}\right)-K^{i}\right) \mathrm{I}_{\left\{s<S^{i}\left(K^{i}\right)\right\}}\right.\right. \\
& \left.\left.+Y^{i}\left(K^{i}\right)\left(s-K^{i}\right) \mathrm{I}_{\left\{s \geq S^{i}\left(K^{i}\right)\right\}}-v^{i}\left(s, K^{i}\right)\right\} \mid F_{0}^{S, K^{i}}\right] .
\end{aligned}
$$

The above expression can equivalently be written

$$
\begin{gathered}
\hat{v}^{P}(s)=\sum_{i=1}^{n}\left\{\int _ { \underline { K } } ^ { \overline { K } } \left\{\frac{\phi(s)}{\phi\left(S^{i}\left(K^{i}\right)\right)} Y^{i}\left(K^{i}\right)\left(S^{i}\left(K^{i}\right)-K^{i}\right) \mathrm{I}_{\left\{s<S^{i}\left(K^{i}\right)\right\}}\right.\right. \\
\left.\left.+Y^{i}\left(K^{i}\right)\left(s-K^{i}\right) \mathrm{I}_{\left\{s \geq S^{i}\left(K^{i}\right)\right\}}-v^{i}\left(s, K^{i}\right)\right\} f\left(K^{i}\right) d K^{i}\right\}
\end{gathered}
$$

Using the relationship in equation (17) we find that

$$
\hat{v}^{P}(s)=\sum_{i=1}^{n}\left\{\int _ { \underline { K } } ^ { \overline { K } } \left\{\frac{\phi(s)}{\phi\left(S^{i}\left(K^{i}\right)\right)} Y^{i}\left(K^{i}\right)\left(S^{i}\left(K^{i}\right)-K^{i}-\frac{F\left(K^{i}\right)}{f\left(K^{i}\right)}\right) \mathrm{I}_{\left\{s<S^{i}\left(K^{i}\right)\right\}}\right.\right.
$$




$$
\left.\left.+Y^{i}\left(K^{i}\right)\left(s-K^{i}-\frac{F\left(K^{i}\right)}{f\left(K^{i}\right)}\right) \mathrm{I}_{\left\{s \geq S^{i}\left(K^{i}\right)\right\}}\right\} f\left(K^{i}\right) d K^{i}\right\} .
$$

The last expression follows from partial integration of

$$
\int_{\underline{K}}^{\bar{K}} \int_{K^{i}}^{\bar{K}} \frac{\phi(s)}{\phi\left(S^{i}(u)\right)} Y^{i}(u) \mathrm{I}_{\left\{s<S^{i}\left(K^{i}\right)\right\}} d u f\left(K^{i}\right) d K^{i}
$$

and

$$
\int_{\underline{K}}^{\bar{K}}\left[\int_{K^{i}}^{\bar{K}} Y^{i}(u)+\int_{\nu^{i}(s)}^{\bar{K}} \frac{\phi(s)}{\phi\left(S^{i}(u)\right)} Y^{i}(u)\right] \mathrm{I}_{\left\{s \geq S^{i}\left(K^{i}\right)\right\}} d u f\left(K^{i}\right) d K^{i}
$$

respectively.

\section{Equality Between the two Approaches of Finding the Optimal Compensation Function}

The probability that agent $i$ wins the contract $Y^{i^{*}}\left(K^{i}\right)$ equals $\left[1-F\left(K^{i}\right)\right]^{n-1}$, i.e., equals the probability of having the lowest cost in a sample of $n$. Substitution of $Y^{i^{*}}\left(K^{i}\right)$ by $\left[1-F\left(K^{i}\right)\right]^{n-1}$ in (23), leads to

$$
\begin{aligned}
X^{i^{*}}\left(s, K^{i}\right) & =K^{i}\left[1-F\left(K^{i}\right)\right]^{n-1}+\int_{K^{i}}^{v^{i^{*}}(s)}[1-F(u)]^{n-1} d u \\
& +\int_{K^{i}}^{v^{i^{*}}(s)} \frac{\phi(s)}{\phi\left(S^{i^{*}}(u)\right)}[1-F(u)]^{n-1} d u
\end{aligned}
$$

If $s>S^{i^{*}}\left(K^{i}\right)$

We will now prove that $X^{i^{*}}\left(s, K^{i}\right)=E\left[\tilde{X}^{i}(s, K) \mid F_{0}^{S, K^{i}}\right]$. We treat $K^{j}$ as the first-order statistic in a sample of size $n-1$, which implies that we assume that $K^{j}$ is the lowest cost parameter in a sample of $n-1$ cost parameters. Evaluation of $E\left[\tilde{X}^{i}(s, K) \mid F_{0}^{S, K^{i}}\right]$ leads to 


$$
\begin{gathered}
E\left[\tilde{X}^{i}(s, K) \mid F_{0}^{S, K^{i}}\right]=\int_{K^{i}}^{\vartheta^{i^{*}}(s)} K^{j} d\left(-\left[1-F\left(K^{j}\right)\right]^{n-1}\right) \\
+\int_{v^{\psi^{*}}(s)}^{\bar{K}}\left(\vartheta^{i^{*}}(s)+\int_{\vartheta^{j^{*}}(s)}^{K^{j}} \frac{\phi(s)}{\phi\left(S^{i^{*}}(u)\right)} d u\right) d\left(-\left[1-F\left(K^{j}\right)\right]^{n-1}\right)
\end{gathered}
$$

when $s \geq S^{i^{*}}\left(K^{i}\right)$. Partial integration of equation (30) leads to

$$
\begin{aligned}
E\left[\tilde{X}^{i}(s, K) \mid F_{0}^{S, K^{i}}\right]= & K^{i}\left[1-F\left(K^{i}\right)\right]^{n-1}+\int_{K^{i}}^{v^{i *}(s)}[1-F(u)]^{n-1} d u \\
& +\int_{v^{*}(s)}^{\bar{K}} \frac{\phi(s)}{\phi\left(S^{i^{*}}(u)\right)}[1-F(u)]^{n-1} d u
\end{aligned}
$$

if $s \geq S^{i^{*}}\left(K^{i}\right)$. Equation (31) equals equation (29), and thus equals equation (23).

\section{References}

Antle, R.; Bogetoft, P.; and Stark, A. W. 2001. Information systems, incentives and the timing of investments. Journal of Accounting and Public Policies 20: 267-294.

Bjerksund, P., and Ekern, S. 1990. Managing investment opportunities under price uncertainty: from "last chance" to "wait and see" strategies. Financial Management, Autumn. Reprinted in Schwartz, E., and Trigeorgis, L. (eds). Real Options and Investment under Uncertainty: Classical Readings and Recent Contributions. MIT Press, 2001.

Bjerksund, P., and Stensland, G. 2000. A self-enforced dynamic contract for processing of natural resources. In Brennan, M. J., and Trigeorgis, L.(eds). Project Flexibility, Agency, and Competition: New Developments in the Theory and Application of Real Options. Oxford University Press.

Borodin, A. N., and Salminen, P. 1996. Handbook of Brownian Motion - Facts and Formulae. Birkhauser Verlag, Basel.

Brennan, M., and Schwartz, E. 1985. Evaluating natural resource investments. Journal of Business 58: 135-157.

Dixit, A., and Pindyck, R. S. 1994. Investment under Uncertainty. Princeton 
University Press.

Grenadier, S. R. 1996. The strategic exercise of options: development cascades and overbuilding in real estate markets. Journal of Finance 51 (5).

Grenadier, S. R. 1999. Information revelation through option exercise. The Review of Financial Studies 12 (1), 95-129.

Grenadier, S. R., and Wang, N. E. 2005. Investment Timing, Agency and Information. Journal of Financial Economics 75 (3): 493-533.

Itô, K., and McKean, H. P. J. 1965. Diffusion processes and their sample paths. (1st ed). Springer.

Klemperer, P. 1999. Auction theory: a guide to the literature. Journal of Economic Surveys 13 (3): 227-286. Reprinted in The Economic Theory of Auctions. Klemperer, P. (ed.), Edward Elgar (pub.), Cheltenham, UK, 2000: 3-62. Also reprinted in The current State of Economic Science. Dahiya, S (ed.), 1999, Vol. 2: 711-766.

Laffont, J.-J., and Tirole, J. 1987. Auctioning incentive contracts. Journal of Political Economy 95 (5): 921-937.

Laffont, J.-J., and Tirole, J. 1993. A Theory of Incentives in Procurement and Regulation. MIT Press, MIT, Massachusettes.

Mæland, J. 2002. Valuation of irreversible investments and agency problems.Forthcoming in Trigeorgis, L. (ed.). Innovation, Organization and Strategy. Cambridge University Press.

McDonald, R., and Siegel, D. 1986. The value of waiting to invest. Quarterly Journal of Economics 101: 707-727.

Melumad, N. D., and Reichelstein, S. 1989. Value of communication in agencies. Journal of Economic Theory 47: 334-368.

Moel, A., and Tufano, P. 2000. Bidding for the Antamina mine. In Brennan, M. J., and Trigeorgis, L. (eds). Project Flexibility, Agency, and Competition: New Developments in the Theory and Application of Real Options. Oxford University Press.

Myerson, R. B. 1981. Optimal auction design. Mathematics of Operations Research 6 (1): 58-73.

Paddock, J. L.; Siegel, D. R.; and Smith, J. L. 1988. Option valuation of claims on real assets: the case of offshore petroleum leases. Quarterly Journal of Economics, August: 479-508.

Riley, J. G., and Samuelson, W. F. 1981. Optimal auctions. The American Economic Review 71 (3): 381-392.

Salanié, B. 1997. The Economics of Contracts. A Primer. The MIT Press.

Vickrey, W. 1961. Counterspeculation, auctions, and competitive sealed tenders. Journal of Finance 16: 8-37. 